\title{
Spanish translation and preliminary validation of the Pain
}

\section{Treatment Satisfaction Scale [version 1; peer review: 2}

\section{approved with reservations]}

\section{Teresa A. Nava-Obregon'1, Daniel A. Fragoso-Estrada1, Sandra Castillo-Guzman (iD1, Norma G. Lopez-Cabrera1, Omar González-Santiago (iD)2, Dionicio Palacios-Rioas ${ }^{1}$}

\footnotetext{
${ }^{1}$ Pain and Palliative Care Clinic, Anesthesiology Service, Dr Jose E González University Hospital, Nuevo León, Mexico

${ }^{2}$ Postgraduate division of the Faculty of Chemical Science, Universidad Autonoma de Nuevo León, Nuevo León, Mexico
}

\section{V1 First published: 25 May 2016, 5:996 \\ https://doi.org/10.12688/f1000research.8750.1}

Latest published: 25 May 2016, 5:996

https://doi.org/10.12688/f1000research.8750.1

\begin{abstract}
Satisfactory pain treatment could prevent adverse physical and psychological outcomes in patients. In this sense, adequate survey to measure patient satisfaction of pain management is important. In this study, we translated the Pain Treatment Satisfaction Scale to Spanish and analyzed the psychometric properties of its five dimensions. Reliability was determined with Chronbach's-a and convergent and divergent validity with a multitrait-multimethod analysis. The latter were reported as successful percentage. In the five dimensions, the reliability of the Spanish version showed Chronbach's- $\alpha$ values $\geq 0.75$; successful percentage for convergent validity was $\geq 88$, and successful percentage for divergent validity was $\geq 94$. The Spanish version showed good psychometric properties and can be used to measure pain treatment satisfaction.
\end{abstract}

Keywords

Treatment satisfaction, Pain treatment, PSTT, Mexico

\section{Open Peer Review}

Approval Status ? ?

2

version 1

25 May 2016

$\begin{array}{cc}? & ? \\ \text { view } & \text { view }\end{array}$

1. Frédérique Servin, CHU Bichat Claude Bernard, Paris, France

2. Richard Fielding, The University of Hong

Kong, Hong Kong, Hong Kong

Any reports and responses or comments on the article can be found at the end of the article. 
Corresponding author: Sandra Castillo-Guzman (castilloguzsan@yahoo.com.mx)

Competing interests: No competing interests were disclosed.

Grant information: The author(s) declared that no grants were involved in supporting this work.

Copyright: $\odot 2016$ Nava-Obregon TA et al. This is an open access article distributed under the terms of the Creative Commons Attribution License, which permits unrestricted use, distribution, and reproduction in any medium, provided the original work is properly cited. The author(s) is/are employees of the US Government and therefore domestic copyright protection in USA does not apply to this work. The work may be protected under the copyright laws of other jurisdictions when used in those jurisdictions. Data associated with the article are available under the terms of the Creative Commons Zero "No rights reserved" data waiver (CC0 1.0 Public domain dedication).

How to cite this article: Nava-Obregon TA, Fragoso-Estrada DA, Castillo-Guzman S et al. Spanish translation and preliminary validation of the Pain Treatment Satisfaction Scale [version 1; peer review: 2 approved with reservations] F1000Research 2016, 5 :996 https://doi.org/10.12688/f1000research.8750.1

First published: 25 May 2016, 5:996 https://doi.org/10.12688/f1000research.8750.1 


\section{Introduction}

Satisfactory pain management is important to prevent adverse physical and psychological results for patients and their families. Through the activation of the pituitary-adrenal axis, inadequate pain treatment could produce postsurgical infection and poor wound healing. Pain also actives the sympathetic nervous system, which results in disruption of the cardiovascular, gastrointestinal and renal systems ${ }^{1}$. In addition, patients with pain may have a sense of helplessness or hopelessness. This may predispose them to anxiety and depression, and they may be reluctant to seek medical care for other health problems ${ }^{2}$.

Adequate pain control can improve the patient's attitudes and behaviors toward their treatment. They are more willing to comply with the advice of their health care provider, miss fewer medical appointments and are more likely to adhere to their medical treatment ${ }^{3}$. In this sense, surveys to measure patient satisfaction and pain treatment are important for adequate health care. The aim of this study was to translate the Pain Treatment Satisfaction Scale (PTSS) ${ }^{4}$ into Spanish and analyze some of its psychometric properties.

\section{Methods}

Survey. The PTSS was developed by Evans et $a l .{ }^{4}$ and validated to assess satisfaction in patients with both acute and chronic pain. This survey includes 39 items grouped into five dimensions: information about your pain and treatment (5 items); medical care (8 items); impact of current pain medication (8 items); satisfaction with pain medication, which included the two subscales medication characteristics ( 3 items) and efficacy ( 3 items); and side effects (12 items). Each item is measured with a 5 point-Likert scale which ranges from 1 (major satisfaction) to 5 (worst satisfaction). Scales and items were transformed to a 0 to 100 score, where 100 represents highest satisfaction.

Translation. This process was carried out in 4 steps. In the first step, 2 authors, experts in pain medicine (TANO and SCG), performed the translation from English to Spanish. In the second step, all authors reviewed the translation and gave suggestions and recommendations to improve the clarity of the items. In the third step, external professional translators made the inverse translation from Spanish to English. In the final step, all authors reviewed both the inverse translation and the original survey.
Sample. We applied the Spanish version to a random sample of 174 patients from the Dr José E. Gonzalez University Hospital with some type of pain. They were interviewed in the postoperative or ambulatory areas. Patients older than 18 years who gave verbal consent were included in this study. The Ethical Committee of the Faculty of Medicine of the Autonomous University of Nuevo León approved this study, and exempted from written informed consent. The reference number is AN15-004.

Statistical analysis. Results of each dimension were calculate. Reliability was measured with Chronbach's alpha test. The criterion of acceptability was 0.7 . The construct validity, which included convergent and divergent validity, was evaluated with a multitraitmultimethod analysis. Convergent validity and divergent validity were expressed as \% successful. Convergent validity was calculated with the following formula \%successful $=[$ (correlations "item-dimension to which it belongs $>0.4$ ")/(total correlations "item-dimension to which it belongs")]*100. The formula for divergent validity was \% successful $=[$ (number of correlations item - dimension lesser that correlations item-dimension to which it belongs)/(total correlations item-dimension to which it does not belong)]*100. Correlations were obtained with the matrix multitrait-multimethod. The statistical software SPSS 21 and the package Psy for R 3.2.2 were used for the analyses.

\section{Results}

Dataset 1. Raw data for 'Spanish translation and preliminary validation of the Pain Treatment Satisfaction Scale'

http://dx.doi.org/10.5256/f1000research.8750.d122791

The final Spanish version of the PTSS is available as supplementary material. Of the patients surveyed, $53.5 \%$ were men and $46.5 \%$ were women. Overall, mean age was 41.5 years, and according to gender, the mean age of women was 38.5 years and for men 44.6 years. The type of pain identified was acute in $60.8 \%$ (postoperative $15.2 \%$ ) and chronic in $39.2 \%$ of patients.

Results of the PTSS are presented in Table 1. In general, patients with mild pain in the last 24 hours had a better score than patients with moderate or intense pain in almost all dimensions, except "side effects".

Table 1. Mean PTSS scores of pilot sample according to pain severity in the last week and last 24 hours.

\begin{tabular}{|l|l|l|l|l|l|l|l|}
\hline & \multicolumn{3}{|c|}{ Intensity of pain in previous 24 Hrs } & \multicolumn{3}{l|}{ Intensity of pain in the previous week } \\
\hline & Mild & Moderate & Intense & Mild & Moderate & Intense \\
\hline Dimension & Information about pain and its treatment & 57.0 & 49.0 & 51.2 & 55.8 & 51.0 & 51.0 \\
\hline Medical care & 59.6 & 64.2 & 56.0 & 61.8 & 61.0 & 60.0 \\
\hline Impact of current pain medication & 66.2 & 62.6 & 54.6 & 63.4 & 65.4 & 57.0 \\
\hline Side effects & 88.0 & 89.2 & 88.4 & 87.2 & 88.6 & 88.6 \\
\hline Satisfaction with current pain medication & 66.0 & 64.4 & 55.8 & 62.2 & 65.2 & 59.4 \\
\hline
\end{tabular}

VAS scale for pain mild $=1-3 ;$ moderate $=4-7 ;$ intense $=8-10$ 
Reliability and construct validity. The range of Chronbach's alpha was 0.75 to 0.90 , with medical care being the dimension with the lowest score and "impact of current pain medication" the dimension with the highest score. The \%successful in convergent and divergent validity ranged from 88 to $100 \%$ and from 94 to $100 \%$, respectively. "Medical care" (88\%) and "side effects" $(92 \%)$ were the dimensions with the lowest \%successful in convergent validity, while medical care $(94 \%)$ was the dimension with the lowest \%successful in discriminant validity.

\section{Discussion}

In this study, we translated and preliminarily evaluated the psychometric properties of PTSS in its Spanish version. In other studies, this survey has been translated and validated in Chinese ${ }^{3}$ and French ${ }^{4}$ where good psychometric properties have been shown.
In the case of reliability, values obtained are satisfactory since values of all dimensions were $>0.70$ and similar to the original version. In general, the values of all dimensions were slightly lower than the original version.

With respect to convergent and discriminant validity, results are satisfactory and similar to the original version. The medical care dimension had lower values than the original in both convergent and discriminant validity. Side effects had a value slightly higher than the original. The rest of the dimensions had the same values as those of the original version.

The limitations of this study include lack of a rigorous diagnosis of the type of pain. The sample size was smaller than that used in other studies ${ }^{3-5}$ and finally, a test-retest analysis was not performed.

\section{Table 2. Reliability of each dimension of the translated version and the original version.}

\begin{tabular}{|l|l|l|l|}
\hline & & \multicolumn{2}{|l|}{ Reliability (Cronbach's Alpha) } \\
\hline Dimension & No. of items & Spanish version & Original version* \\
\hline $\begin{array}{l}\text { Information about pain and its } \\
\text { treatment }\end{array}$ & 5 & 0.86 & 0.89 \\
\hline Medical care & 8 & 0.75 & 0.86 \\
\hline Impact of current pain medication & 8 & 0.90 & 0.92 \\
\hline Side effects & 12 & 0.86 & 0.83 \\
\hline $\begin{array}{l}\text { Satisfaction with current pain } \\
\text { medication }\end{array}$ & 6 & 0.89 & 0.90 \\
\hline
\end{tabular}

*From Evans $2004^{3}$

Table 3. Convergent and divergent validity of each dimension of the translated version and the original version.

\begin{tabular}{|c|c|c|c|c|c|}
\hline \multirow[b]{2}{*}{ Dimension } & \multirow{2}{*}{$\begin{array}{l}\text { Range } \\
\text { correlations } \\
\text { item-scale this } \\
\text { study }\end{array}$} & \multicolumn{2}{|c|}{ Convergent validity } & \multicolumn{2}{|c|}{ Discriminant validity } \\
\hline & & $\begin{array}{l}\text { Success rate } \\
\text { in this study }\end{array}$ & $\begin{array}{l}\text { Success rate* } \\
\text { original version }\end{array}$ & $\begin{array}{l}\text { Success rate } \\
\text { in this study }\end{array}$ & $\begin{array}{l}\text { Success rate* } \\
\text { original version }\end{array}$ \\
\hline $\begin{array}{l}\text { Information about pain and its } \\
\text { treatment }\end{array}$ & $0.54-0.75$ & 100 & 100 & 100 & 100 \\
\hline Medical care & $0.07-0.56$ & 88 & 100 & 94 & 100 \\
\hline Impact of current pain medication & $0.57-0.75$ & 100 & 100 & 100 & 100 \\
\hline Side effects & $0.38-0.66$ & 92 & 83 & 100 & 100 \\
\hline $\begin{array}{l}\text { Satisfaction with current pain } \\
\text { medication }\end{array}$ & $0.64-0.77$ & 100 & 100 & 100 & 100 \\
\hline
\end{tabular}

${ }^{*}$ From Evans $2004^{3}$ 


\section{Conclusion}

The Spanish version of PTSS has satisfactory psychometric properties and some of these are similar to the original version; therefore it could be considered a valid instrument to measure pain treatment satisfaction in a Mexican population.

\section{Data availability}

F1000Research: Dataset 1. Raw data for 'Spanish translation and preliminary validation of the Pain Treatment Satisfaction Scale', 10.5256/f1000research.8750.d1227916

Author contributions

TANO and SCG conceived the study, DAFE an NGLC carried out the research, OGS and DPR prepared the first draft of the manuscript and performed the statistical analysis. All authors were involved in the revision of the draft manuscript and have agreed to the final content.

\section{Competing interests}

No competing interests were disclosed.

Grant information

The author(s) declared that no grants were involved in supporting this work.

\section{Acknowledgments}

Sergio Lozano Scientific Publications Support Coordinator Office of the Vice Dean of Research

"Dr. Jose Eleuterio Gonzalez" University Hospital, Universidad Autónoma de Nuevo León, Monterrey, N.L., Mexico.

\section{Supplementary material}

Spanish version of the PTSS.

1. Wells N, Pasero C, McCaffery M: Improving the Quality of Care Through Pain Assessment and Management. In: Hughes RG, editor. Patient Safety and Quality: An Evidence-Based Handbook for Nurses. Rockville (MD): Agency for Healthcare Research and Quality (US); 2008. PubMed Abstract

2. Hirsh AT, Atchison JW, Berger JJ, et al.: Patient satisfaction with treatment for chronic pain: predictors and relationship to compliance. Clin J Pain. 2005; 21(4): 302-310. PubMed Abstract

3. Wong WS, Chen PP, Chow YF, et al:: The Reliability and Validity of the Cantonese Version of the Pain Treatment Satisfaction Scale (ChPTSS) in a Sample of Chinese Patients with Chronic Pain. Pain Med. 2015; 16(12): 2316-2323.

PubMed Abstract | Publisher Full Text
4. Jouini G, Choinière M, Dion $\mathrm{D}$, et al:: Programme ACCORD: validation of a French version of the pain treatment satisfaction scale in primary care patients with non-cancer chronic pain [abstract]. Annual conference of the Canadian Association for Population Therapeutics; March 28-30, 2010; Toronto, Canada. Can J Clin Pharmacol. 2010; 17(1): e117, 58. Toronto, Canada.
Reference Source

5. Evans CJ, Trudeau E, Mertzanis P, et al.: Development and validation of the Pain Treatment Satisfaction Scale (PTSS): a patient satisfaction questionnaire for use in patients with chronic or acute pain. Pain. 2004; 112(3): 254-266. PubMed Abstract | Publisher Full Text

6. Nava-Obregon TA, Fragoso-Estrada DA, Castillo-Guzman S, et al.: Dataset 1 in: Spanish translation and preliminary validation of the Pain Treatment Satisfaction Scale. F1000Research. 2016. Data Source 


\section{Open Peer Review}

\section{Current Peer Review Status: ? ?}

\section{Version 1}

Reviewer Report 14 September 2016

https://doi.org/10.5256/f1000research.9416.r16266

(C) 2016 Fielding R. This is an open access peer review report distributed under the terms of the Creative Commons Attribution License, which permits unrestricted use, distribution, and reproduction in any medium, provided the original work is properly cited.

\section{Richard Fielding \\ School of Public Health, The University of Hong Kong, Hong Kong, Hong Kong}

I've looked at the paper and generally it reads well, and doesn't seem to have many major problems methodologically, other than the fact that normally, for convergent and divergent validity, different scales that measure similar and dissimilar dimensions are used.

What the authors refer to as divergent and convergent validity in their manuscript when they compare the Spanish and English versions. This is simply the concordance between the scores of English and Spanish instruments, which gives between $88 \%-100 \%$ concordance. This simply might reflect language proficiency effects. I would suggest, therefore that the authors choose some other term for this than convergent and divergent validity as this is incorrect.

Competing Interests: No competing interests were disclosed.

I confirm that I have read this submission and believe that I have an appropriate level of expertise to confirm that it is of an acceptable scientific standard, however I have significant reservations, as outlined above.

Reviewer Report 11 July 2016

https://doi.org/10.5256/f1000research.9416.r13978

(C) 2016 Servin F. This is an open access peer review report distributed under the terms of the Creative Commons Attribution License, which permits unrestricted use, distribution, and reproduction in any medium, provided the original work is properly cited.

\section{Frédérique Servin}

Departement Anesthesie et Reanimation Chirurgicale, CHU Bichat Claude Bernard, Paris, France The paper "Spanish translation and preliminary validation of the Pain Treatment Satisfaction 
Scale" evaluates the validity of an already published pain treatment satisfaction scale, presented in a Spanish translation, on a Mexican population. After a careful double checked translation, the paper concludes that it is adequate for use in the pre-defined population.

This paper is published as a Research note, and indeed, considering the number of items included in the score (39), it can hardly be proposed in clinical practice for repeated measures.

If the quality of the translation has obviously been well controlled, it is not the case for the study population. No estimation of the number of subjects required to demonstrate the validity of the score has been made, despite the fact that the authors had comparators against which they could perform this estimation. 174 appears as a very low number for a population including both acute and chronic pain in a vast variety of patients. Indeed, if the translation is accurate, any difference in its validity will come mainly from socio-cultural factors in the population. The authors themselves are indeed conscious of this limitation, but they could have easily corrected it.

Competing Interests: No competing interests were disclosed.

I confirm that I have read this submission and believe that I have an appropriate level of expertise to confirm that it is of an acceptable scientific standard, however I have significant reservations, as outlined above.

The benefits of publishing with F1000Research:

- Your article is published within days, with no editorial bias

- You can publish traditional articles, null/negative results, case reports, data notes and more

- The peer review process is transparent and collaborative

- Your article is indexed in PubMed after passing peer review

- Dedicated customer support at every stage

For pre-submission enquiries, contact research@f1000.com

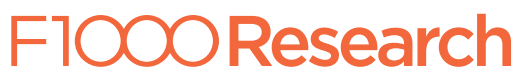

